\title{
Effects of inoculum to feedstock ratio on anaerobic digestion for biogas production
}

\begin{abstract}
Biogas is considered as a clean and a renewable form of energy that could replace the increasing non-renewable energy sources such as fossil fuel for use in heat production and for electricity generation. The inchoate gain in the shift for a renewable source of energy is that the feedstock is often a by-product, a residue or waste product of other processes without the competition for arable land. In this study, five (5) Laboratory scale biodigesters were used for the anaerobic co-digestion of locally available Miscanthus Fuscus and cow dung, controlled at a pH range of 6.2-7.8 and at a mesophilic temperature of $35 \pm 2{ }^{\circ} \mathrm{C}$. Study was also carried out in batch mode at a hydraulic retention time of 33 days. The anaerobic co-digestion process was developed and optimized at varying inoculum to feedstock ratio of 1:0, 0:1, 1:3, 3:1, and 1:1 to determine the potential biogas yield from each proportion. The highest biogas potential was recorded at an inoculum to feedstock ratio of 3:1 with the least biogas potential recorded by the biodigester at a ratio of $0: 1$.
\end{abstract}

Keywords: renewable energy, co-digestion, cow dung, miscanthus fuscus, anaerobic digestion
Volume 2 Issue 5 - 2018

\author{
Asante-Sackey D,' Tetteh EK,' Nkosi N,' \\ Boakye GO, ${ }^{3}$ Ansah Amano KO, ${ }^{4}$ Boamah \\ $\mathrm{BB},{ }^{2}$ Armah EK' \\ 'Department of Chemical Engineering, Durban University of \\ Technology, Durban, South Africa \\ ${ }^{2}$ Department of Pharmacology, Kwame Nkrumah University of \\ Science and Technology, Kumasi, Ghana \\ ${ }^{3}$ Department of Mechanical Engineering, University of Leeds, \\ Leeds, United Kingdom \\ ${ }^{4}$ Department of Chemical Engineering, Biotechnology \\ Laboratory, Kwame Nkrumah University of Science and \\ Technology, P.M.B Kumasi, Ghana
}

\begin{abstract}
Correspondence: Department of Chemical Engineering, Durban University of Technology, Durban, South Africa, Email ektetteh34@gmail.com
\end{abstract}

Received: June 20, 2018 | Published: October 02, 2018

\section{Introduction}

Generation of renewable energy sources remain a vital demand to cater for the ever-increasing energy consumption and the depletion of fossil resources from non-renewable energy. ${ }^{1}$ Studies have been carried out in the past decades to find alternatives for fossil fuel replacement. ${ }^{2}$ Also, urbanization has led to an increase in landfills, and it is estimated that by 2025 , two-thirds of people will be living in the cities globally. ${ }^{3}$ The synthesis of a renewable energy source has been evaluated, where energy is produced from biogas through anaerobic digestion (AD) and technology observed to be promising. ${ }^{4}$ The $\mathrm{AD}$ process to produce bioenergy has gained increasing recognition for the past decades. Biogas is a renewable energy fuel that consists chiefly of $60-70 \%$ methane and $20-30 \%$ carbon dioxide with the presence of other trace compounds such as hydrogen sulfide and ammonia. The gas produced could serve as fuel for electricity generation and also its usage in the production of combined heat and power generation using appropriate technologies. ${ }^{5}$ The $\mathrm{AD}$ process from which biogas is produced involves four major stages as a result of the biodegradation of organic matter by a consortium of microorganisms. ${ }^{6}$ These include hydrolysis, acidogenesis, acetogenesis, and the methanogenesis. In brief, the methanogenic stage which is the final stage is where carbon dioxide produced from the previous processes reacts with the hydrogen present to produce methane and also, at the same time, the acetate break down to form methane and carbon dioxide. ${ }^{7,8}$ Comparatively, anaerobes have been found to be most active at mesophilic conditions than thermophilic conditions as the latter tend to require higher heat input. ${ }^{9}$ However, this present study focused on the former. Limitations such as process instability, process failure, poor methane yield, and longer retention time have limited the full exploitation of the $\mathrm{AD}$ process. ${ }^{10,11}$ Processes such as anaerobic co-digestion, low organic loading to avoid overloading in biodigesters, pretreatment techniques to enhance cellulose and disrupt lignin, and the use of energy crops as feedstocks, have been found to increase the efficacy of biogas production through anaerobic digestion. ${ }^{12-14}$ Recirculation of digested slurry (washed out microbes) back into the reactor and design modification of existing biogas plants are some of the ways that have been used in literature to also improve the gas production in biogas plants. ${ }^{15}$ Process parameters such as temperature, agitation, carbon-nitrogen ratio, organic loading rate, and the hydraulic retention time can be measured by studying and monitoring the variation during the $\mathrm{AD}$ process. ${ }^{16}$ According to Simo et al. ${ }^{17}$ a sharp change in these parameters could adversely affect the biogas production process. For higher efficiencies, these parameters should be varied within a desirable range to operate the biogas plant. Also, one important parameter to consider in the application of anaerobic digestion is the type of feedstock used as almost any organic material can be processed..$^{10}$ Feedstocks utilized in the past decades for biogas production includes waste paper, grass clippings, leftover food, sewage, sugarcane bagasse, and animal waste. However, in this study, Miscanthus Fuscus was used for the AD process to produce biogas. Miscanthus Fuscus is a bamboo-like plant that overgrows up to 3 meters high, generating a high yield of biomass with low ash content and suitable for use in electricity generation. ${ }^{18}$ It is a promising non-food crop yielding a high-quality lignocellulosic material with good fiber content suitable for thatching and also for industrial use. ${ }^{19}$ Literature reports that Miscanthus Fuscus has been found to be suitable for biogas production and has a higher methane potential per unit area. ${ }^{20}$ According to Kiesel \& Lewandowski, ${ }^{21}$ Miscanthus Fuscus, when harvested before winter could increase the yield and digestibility for the $\mathrm{AD}$ process than after winter. The demand to seek ways to improve and increase the yield of biogas has wakened many researchers to quest for alternative ways to cater for this setback because of low yield of methane reported in various researches. This study, however, focuses on the effects of inoculum to feedstock ratio in determining the biogas potential with varying ratios of these substrates. 


\section{Materials and methods}

The biochemical methane potential (BMP) test was carried out to determine the potential of biogas from Miscanthus Fuscus (Figure 1) and cow dung.

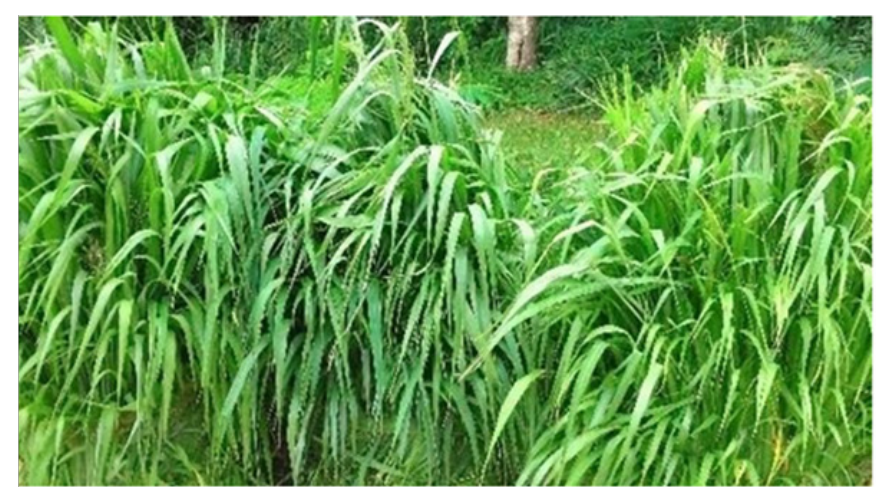

Figure I Photo of Miscanthus Fuscus used for this study.

\section{Material sampling}

Miscanthus Fuscus was harvested from a local farmland at Adako Jachie in the Ashanti region of Ghana, serving as the feedstock. The choice of feedstock was due to its bioavailability for use in energy production. The inoculum, cow dung was obtained from a cattle farm within the same municipality to provide the necessary bacteria for the anaerobic digestion process which was further kept in sealed Schott bottles and stored at $4^{\circ} \mathrm{C}$ prior for analysis.

\section{Characterization of feedstock and inoculum}

Miscanthus Fuscus was sun dried and washed to remove the unwanted particles. It was then shredded, slightly milled with a hammer miller (Fritsch Pulverisette 558, Germany) and sieved to an appreciable size of $5 \mathrm{~mm}$ (on dry weight basis) for further analysis. This was carried out to increase the surface area for better adsorption between substrates during the $\mathrm{AD}$ process. The proximate analysis of the feedstock was performed with parameters such as total solids (TS), moisture content (MC), volatile solids (VS), fixed solids (FS) and ash contents (AC) as in Table 2 by the standard methods. ${ }^{22-24}$ This study however did not include the ultimate analysis. Also, the values for the inoculum characterization are not included in this paper. Standard procedures were carried out in the Laboratory using a precision balance (Kern PCB 3500-2, United Kingdom), a convection oven (VWR DRYline oven, Pennsylvania), a muffle furnace (Nabertherm, China), a $5 \mathrm{~mm}$ sieve, and a dessicator containing dessicant for cooling.

\section{Experimental design for the laboratory setup}

Table 1 depicts the experimental design of the inoculum to feedstock selection for this study corresponding to five (5) biodigesters. However, after feeding the biodigesters at an optimal loading rate, the $\mathrm{pH}$ in each biodigesters selected for this study was monitored within a desired range of 6.0-8.5 according to Kougias \& Angelidaki, ${ }^{25}$ This optimal range was selected as it was found to fall within the same range by most researchers undergoing the $\mathrm{AD}$ process such as that reported by Hallenbeck. ${ }^{26}$ Sodium hydroxide $(\mathrm{NaOH})$ was used to adjust the $\mathrm{pH}$ of the $\mathrm{AD}$ process to cater for volatile fatty acids (VFAs) such as acetates and propionates that would be generated within the biodigesters. Maile et al. ${ }^{27}$ have also reported the use of calcium carbonate $\left(\mathrm{CaCO}_{3}\right)$ and $\mathrm{NaOH}$ as prefered reagents to control the alkalinity of the slurry during the $\mathrm{AD}$ process.

The experimental values obtained from Table 2 are illustrated by the calculations from Equations 1-5 below according to $\mathrm{APHA}^{22}$ as;

$$
\begin{gathered}
\% \text { Total solids }=\frac{(A-B) \times 100 \%}{(C-B)} \\
\% \text { Volatile solids }=\frac{(A-D) \times 100 \%}{(A-B)} \\
\% \text { Fixed solids }=\frac{(D-B) \times 100 \%}{(A-B)} \\
\% \text { Moisturesolids }=100 \%-\frac{(A-B) \times 100 \%}{(C-B)} \\
\% \text { Ash solids }=\frac{\left(M_{d}-M_{a}\right) \times 100 \%}{\left(M_{b}-M_{a}\right)}
\end{gathered}
$$

Where $\mathrm{A}=$ weight of dried residue + dish, in $\mathrm{g}$; $\mathrm{B}=$ weight of dish only, in g; $\mathrm{C}=$ weight of wet sample + dish, in $\mathrm{g} ; \mathrm{D}=$ weight of residue + weight of dish after ignition, in $\mathrm{g} ; \mathrm{M}_{\mathrm{d}}=$ mass of crucible + mass of sample after $600^{\circ} \mathrm{C}$ ashing; $M_{a}=$ mass of crucible only, in $g ; M_{b}=$ mass of crucible + mass of sample before ashing, in $\mathrm{g}$.

Table I Feedstock and the Inoculum experimental design

\begin{tabular}{llll}
\hline Biodigester ID & Inoculum (I) & Feedstock (S) & I/F \\
\hline A & 100 & 0 & $1: 0$ \\
B & 0 & 100 & $0: 1$ \\
C & 25 & 75 & $1: 3$ \\
D & 75 & 25 & $3: 1$ \\
E & 50 & 50 & $1: 1$ \\
\hline
\end{tabular}

Table 2 Results for the proximate analysis of Miscanthus Fuscus

\begin{tabular}{ll}
\hline Parameters & Experimental values (\%) \\
\hline Total solids & 91.0 \\
Moisture content & 9.0 \\
Volatile solids & 76.1 \\
Fixed solids & 23.8 \\
Ash contents & 3.5 \\
\hline
\end{tabular}

\section{The biochemical methane potential (BMP) test}

The characterization values were used to calculate the organic loading rate for each biodigester prior for the BMP test. Each biodigester was a $1000 \mathrm{~mL}$ Duran Schott bottle with a working volume of $800 \mathrm{~mL}$ leaving a headspace of $200 \mathrm{~mL}$. This headspace was purged with nitrogen gas $\left(\mathrm{N}_{2}\right)$ to create the anaerobic environment for about 45 seconds each. Biodigesters were closed air-tight with rubber caps and incubated in a circulating water bath regulated at a mesophilic 
temperature of $35 \pm 2{ }^{\circ} \mathrm{C}$. Since it is a batch system, it was made to run until the $\mathrm{AD}$ process was complete at a hydraulic retention time (HRT) of 33 days. Stirring was done after both substrates were kept in each biodigester prior for the BMP test to ensure uniformity. Biogas yield was verified to determine both the methane and the carbon dioxide contents since these constitute the largest components of gases in the biogas. Qualitatively, biogas was determined using a Gas chromatograph (SRI $8610 \mathrm{GC}$ ) equipped with thermal conductivity detector, packed with 6' Hayesep-D/6' Molecular Sieve-13 X. The volume of biogas produced was determined using the downward displacement method on daily basis as depicted in Figure 2.

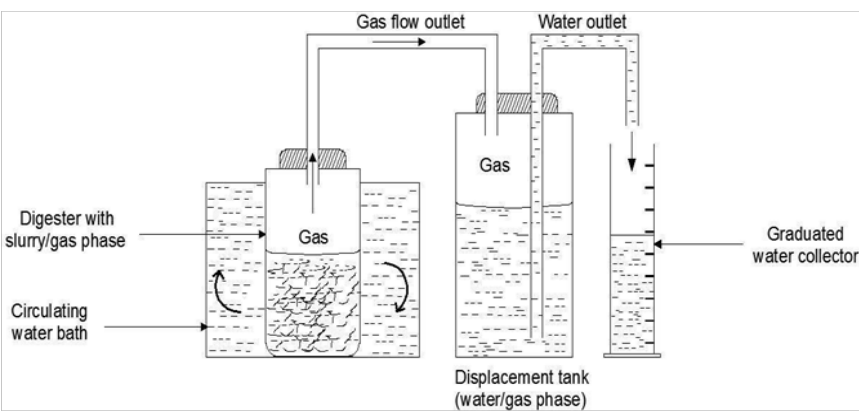

Figure 2 The experimental setup of a single biodigester for the BMP test.

\section{Results and discussion}

A known quantity of inoculum (cow dung reported as raw material) and the feedstock (Miscanthus Fuscus, reported as dry matter) were characterized according to standard methods. The results showed a great methane potential as a significant biodegradable fraction existing in the feedstock.

\section{Biogas production}

The relative daily biogas production rates from the biodigesters containing the substrates were observed under different mixing ratios $(\mathrm{I} / \mathrm{F})$ as depicted in Figure 3. The lag phase occurred during the $1^{\text {st }}$ day as biogas production commenced afterwards. It was evident that there was pressure build-up in the headspace of each biodigester as biogas production rate remained constant until the $15^{\text {th }}$ day. It is however observed that the biogas rate increased in all the biodigesters from the $15^{\text {th }}$ day, a sharp drop on the $18^{\text {th }}$ day and rose again on the $22^{\text {nd }}$ day as shown in Figures 3-5. However, biogas production started to decrease from the $30^{\text {th }}$ day until on the $33^{\text {rd }}$ day, when it ceased. This is because the microorganisms responsible for the degradation during the $\mathrm{AD}$ process might have been consumed up leading to the seizure of the entire process on the $33^{\text {rd }}$ day. The results also show that on the $21^{\text {st }}$ day, a higher biogas rate of $1 \mathrm{ml} / \mathrm{kg}$ was produced from biodigester $\mathrm{D}(\mathrm{I} / \mathrm{F}$ ratio of $3: 1$ ), followed by $\mathrm{E}$ (ratio $1: 1$ ) of $0.9 \mathrm{ml} / \mathrm{kg}$ and then $\mathrm{C}$ (ratio $1: 3$ ) of $0.8 \mathrm{ml} / \mathrm{kg}$ as in Figure 3. Similarly, biodigesters A and $\mathrm{B}$ produced the least amount of biogas, both at a rate of $0.7 \mathrm{ml} /$ kg. Therefore, exposing cow dung and Miscanthus Fuscus to same operating conditions can resolve in producing almost the same amount of biogas. ${ }^{16}$

\section{Biogas composition of methane $\left(\mathrm{CH}_{4}\right)$ and carbon dioxide $\left(\mathrm{CO}_{2}\right)$}

Comparatively, there have been several reports from literature on the percentage yield of methane and carbon dioxide. Biogas consists of about $60 \%$ methane $\left(\mathrm{CH}_{4}\right)$ and $36-37 \%$ carbon dioxide $\left(\mathrm{CO}_{2}\right)$ with the presence of other trace gases such as $\mathrm{H}_{2} \mathrm{~S}$ and $\mathrm{NH}_{3} \cdot{ }^{28}$ However, in this study, the biogas produced shows a higher methane production on daily basis as compared to carbon dioxide as depicted in Figure 4 \& Figure 5respectively, an indication of trend as presented in literature. It was also shown that biodigester $\mathrm{D}$ with $\mathrm{I} / \mathrm{F}$ ratio of $3: 1$ contributed to the highest methane yield as compared to biodigesters A, B, C and E. This is attributed to the balance between the amount of inoculum and the feedstock presence in the biodigester $\mathrm{D}$ whiles the rest of the biodigesters received setbacks of unbalanced inoculum to feedstock ratio. This eventually affected the microorganism and, in some cases, could lead to shortage rendering the process unstable and could lead to possible reactor failure. For 33 days, the average methane recorded was $0.31,0.3,0.36,0.46$ and $0.4 \mathrm{ml} / \mathrm{kg}$ for biodigesters $\mathrm{A}, \mathrm{B}, \mathrm{C}, \mathrm{D}$, and E respectively. Likewise, the $\mathrm{CO}_{2}$ recorded were $0.14,0.14,0.17,0.21$ and $0.18 \mathrm{ml} / \mathrm{kg}$ for biodigesters A, B, C, D, and E respectively. Besides biodigester $\mathrm{D}$ generating the highest amount of biogas, a combination of the inoculum and feedstock in the ratio of 1:1 also showed a high probability of generating biogas as depicted in Figure 6.

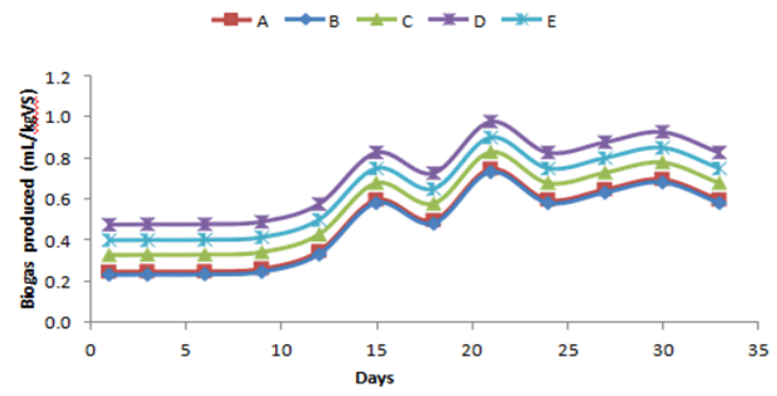

Figure 3 Effect of I/F ratio on daily biogas production ( $\mathrm{ml} / \mathrm{kgVS}$ ).

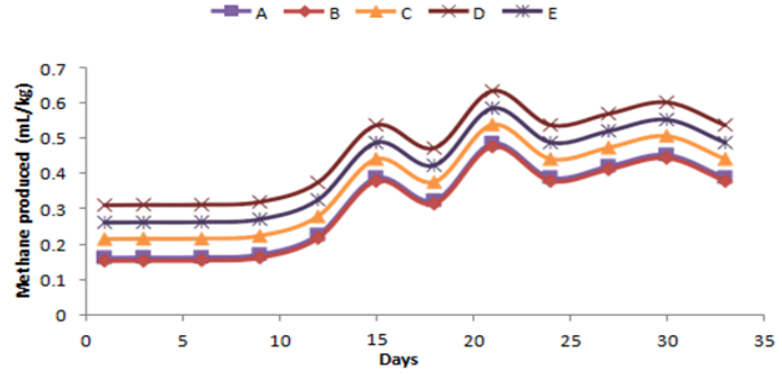

Figure 4 Effect of I/F ratio on daily methane production.

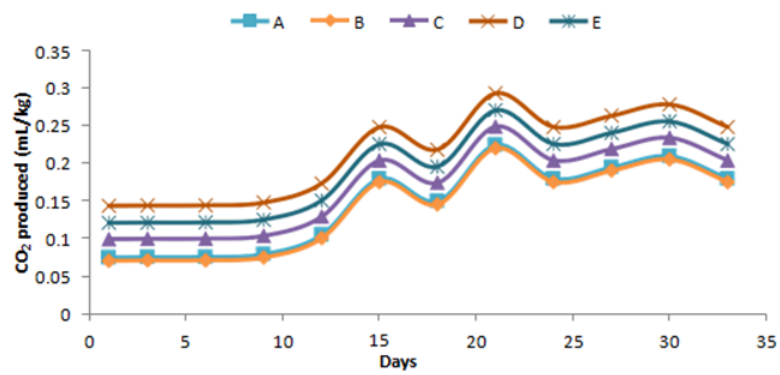

Figure 5 Effect of I/F ratio on daily $\mathrm{CO}_{2}$ production.

\section{Inoculum effects on biogas production}

Figure 6 shows the effect of the inoculum in each biodigester for cow dung and Miscanthus Fuscus for the total biogas production. The results show the biodigesters in decreasing order of biogas production as $\mathrm{D}<\mathrm{E}<\mathrm{C}<\mathrm{A}<\mathrm{B}$ respectively in the ratio (I/F) of $3: 1,1: 1,1: 3,1: 0$ and 
$0: 1$. The total volumes recorded were 8478 for biodigester $\mathrm{D}, 7570$ for biodigester E, 6707 for biodigester C, 5730 for biodigester A and 5552 $\mathrm{ml}$ for biodigester B. From Figure 7, the study also shows that the total biogas production for most of the biodigesters was observed to be higher than for those biodigesters with the absence of an inoculum. This result indicates that a well-balanced mixture of cow dung and Miscanthus Fuscus is an effective and an alternative option to improve the biogas and methane yield within a specified hydraulic retention time. Thus, the presence of an inoculum in a biodigester during an $\mathrm{AD}$ process contributes greatly to the produced biogas. ${ }^{29}$ Also, in brief, it could be stated that the greater the ratio of the inoculum to a feedstock in a biodigester, the better the biogas output as compared to biodigesters with less or without inoculum fractions. The lowest biogas and methane yields observed in biodigester B (containing only Miscanthus Fuscus) gives an indication for the absence of bacteria responsible for the biodegradation during the AD process. ${ }^{16}$ In other studies, such loading in the absence of an inoculum for biodegradation could easily lead to reactor failure and a much shorter retention time lasting for less than 10 days. ${ }^{11}$

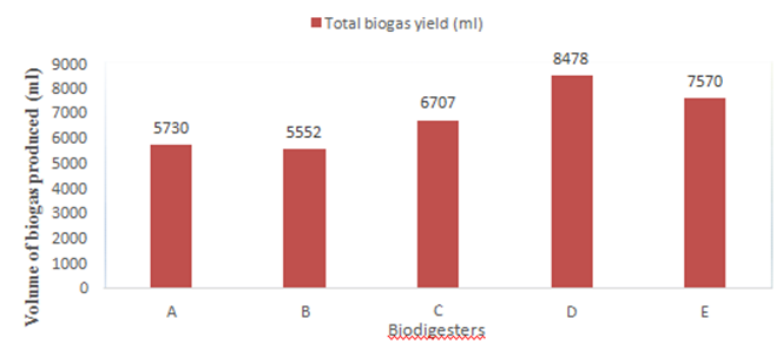

Figure 6 Biogas produced per each biodigester (I/F ratio).

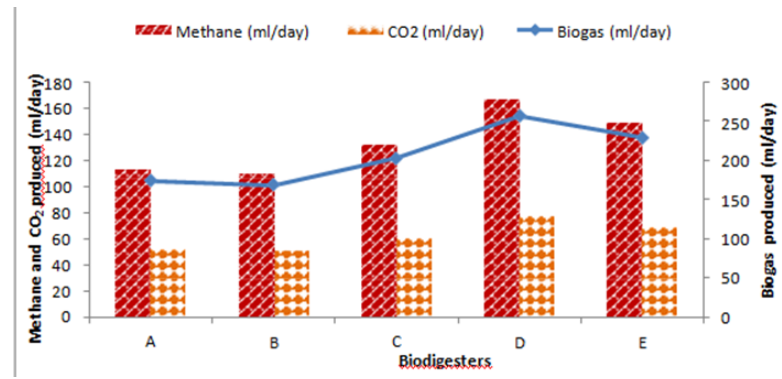

Figure 7 Overview of biogas composition produced per each biodigester (I/F ratio).

\section{Conclusion}

Biogas production via anaerobic co-digestion of Miscanthus Fuscus with cow dung was found to be a potential resource for energy production. Biodigester D containing these substrates at an $\mathrm{I} / \mathrm{F}$ ratio of 3:1 reported the highest potential for biogas production with a total volume of biogas of $8478 \mathrm{~mL}$ in this study for the BMP test. Average biogas production for the same biodigester was reported to be $0.4 \mathrm{ml} /$ $\mathrm{kg}$ during the 33 days of anaerobic digestion. The results indicated that biogas and methane production in the presence of an inoculum increases the yield output than biodigester's without the presence of an inoculum. Therefore, a well-balanced inoculum to feedstock ratio is an effective way of improving the yield of biogas via anaerobic digestion. It is therefore warranted to researchers to focus on the utilization of Miscanthus Fuscus with an inoculum in a definite proportion as both substrates have the potential to produce higher biogas yield. This could in turn be used to ease the dependency on fossil fuels and other non-renewable sources of energy.

\section{Acknowledgements}

The authors are thankful to the affiliate University for the use of the Laboratory facilities during this study.

\section{Conflict of interest}

The authors of this manuscript declare that there is no conflict of interest.

\section{References}

1. Sørensen A, Lübeck M, Lübeck PS, et al. Fungal beta-glucosidases: a bottleneck in industrial use of lignocellulosic materials. Biomolecules. 2013;3(3):612-631.

2. $\mathrm{Gu} \mathrm{H}$, Zhang $\mathrm{K}$, Wang $\mathrm{Y}$, et al. Waste biomass from production process co-firing with coal in a steam boiler to reduce fossil fuel consumption: A case study. Journal of Energy Chemistry. 2013;22(3):413-419.

3. Troschinetz AM, Mihelcic JR. Sustainable recycling of municipal solid waste in developing countries. Waste management. 2009;29(2):915-923.

4. El-Mashad HM, Zhang R. Biogas production from co-digestion of dairy manure and food waste. Bioresource technology. 2010;101(11):4021-4028.

5. Maile I, Muzenda E, Mbohwa C. Biochemical methane potential of OFMSW for City of Johannesburg. 2016.

6. Khanal SK. Anaerobic biotechnology for bioenergy production: principles and applications. John Wiley \& Sons. 2011.

7. Saady NMC, Massé DI. Impact of organic loading rate on psychrophilic anaerobic digestion of solid dairy manure. Energies. 2015;8(3):1990-2007.

8. Sun Y, Cheng J. Hydrolysis of lignocellulosic materials for ethanol production: a review. Bioresource technology. 2002;83(1):1-11.

9. Mital K. Biogas systems: policies, progress and prospects. Taylor \& Francis. 1997.

10. Armah EK, Tetteh EK, Boamah BB. Overview of biogas production from different feedstocks. International Journal of Scientific and Research Publications. 2017;7(12):158-164.

11. Nges IA, Björnsson L. High methane yields and stable operation during anaerobic digestion of nutrient-supplemented energy crop mixtures. Biomass and bioenergy. 2012;47:62-70.

12. Alvira P, Tomás-Pejó E, Ballesteros $\mathrm{M}$, et al. Pretreatment technologies for an efficient bioethanol production process based on enzymatic hydrolysis: a review. Bioresource technology. 2010;101(13):4851-4861.

13. Eliyan C. Anaerobic digestion of municipal solid waste in thermophilic continuous operation. In: School of Environment, Resource and Development. 2007;1-25.

14. Ribeiro FR, Passos F, Gurgel LVA, et al. Anaerobic digestion of hemicellulose hydrolysate produced after hydrothermal pretreatment of sugarcane bagasse in UASB reactor. Science of the Total Environment. 2017;584:1108-1113.

15. Sreekrishnan T, Kohli S, Rana V. Enhancement of biogas production from solid substrates using different techniques - a review. Bioresource technology. 2004;95(1):1-10.

16. Tetteh EK, Amano KOA, Asante-Sackey D. Biochemical Methane Potential (BMP) of Miscanthus Fuscus for Anaerobic Digestion. 
International Journal of Scientific and Research Publication. 2017;7(12):434-439.

17. Simo WSF, Jong NE, Kapseu C. Improving Biogas Production of Sugarcane Bagasse by Hydrothermal Pretreatment. Chemical and Biomolecular Engineering. 2016;1(1):21-25.

18. Wagner M, Kiesel A, Hastings A, et al. Novel miscanthus germplasmbased value chains: A Life Cycle Assessment. Frontiers in Plant Science. 2017;8:990

19. Jones MB, Walsh M. Miscanthus for Energy and Fibre. Earthscan London: United Kingdom; 2001.

20. Mayer F, Gerin PA, Noo A, et al. Assessment of energy crops alternative to maize for biogas production in the Greater Region. Bioresource technology. 2014;166:358-367.

21. Kiesel A, Lewandowski I. Miscanthus as biogas substrate-Cutting tolerance and potential for anaerobic digestion. Gcb Bioenergy. 2017;9(1):153-167.

22. APHA. Standard Methods for the Examination of Water and Wastewater. Washington DC: USA; 1998.
23. Ehrman T. Standard methods for determination of Total solids in Biomass. In: Chemical Analysis and Testing Task (Laboratory Analytical Procedure, LAP-001). 1994;1-7.

24. Sluiter A, Hames B, Ruiz R, et al. Determination of structural carbohydrates and lignin in biomass. Laboratory analytical procedure. 2008;1617:1-16.

25. Kougias PG, Angelidaki I. Biogas and its opportunities-A review. Frontiers of Environmental Science \& Engineering. 2018;12:1-12.

26. Hallenbeck PC. Microbial Technologies in Advanced Biofuels Production. New York: Springer Science; 2011.

27. Maile IO, Muzenda E, Mbohwa C. Biochemical Methane Potential of OFMSW for City of Johannesburg. San Francisco on 26-28. 2016.

28. Abbasi T, Tauseef S, Abbasi S. Anaerobic digestion for global warming control and energy generation - an overview. Renewable and Sustainable Energy Reviews. 2012;16(5):3228-3242.

29. Lawal A, Dzivama A, Wasinda M. Effect of inoculum to substrate ratio on biogas production of sheep paunch manure. Research in Agricultural Engineering. 2016;62(1):8-14. 